\title{
The Challenge of the Trafficked Girls in the Difficult Process of the Reintegration
}

\author{
Alisa Biçoku \\ PhD. Cand, Lecturer at the Department of Social Science, \\ Faculty of Education Sciences, "Alexander Xhuvani" University, Elbasan, Albania. \\ Denisa Ballhysa \\ MSc, Lecturer at the Department of Social Science, \\ Faculty of Education Sciences, "Alexander Xhuvani" University, Elbasan, Albania.
}

\section{Abstract}

\begin{abstract}
The reintegration refers to the process of trafficked girls ' involvement in social and economic life. This process, which is important for trafficked women's life remains a long process to achieve. This study focuses on its core trafficked girls who are going through the long high of social reintegration. The aim of this study is to analyze the significance of experiences, emotions, social and economic difficulties that need trafficked girls face during reintegration into society. The specific objective of this study is the importance of the reintegration process and the factors that influence the success of this process in the social life of victims of trafficking. The methodology used in this study is qualitative, as an efficient method that provides a sense of depth to the exploration of subjects, giving us much more detailed and specific information. The tools that have been used are the focus group, organized in collaboration with girls' victims of trafficking which are secured in the Centre "Vatra".
\end{abstract}

Keywords: victim of trafficking, reintegration process, assessment.

\section{Literature review for the provision of social model in assisting victims of trafficking}

Reintegration refers to the process of recovery and socio-economic inclusion of individuals following a trafficking experience. Reintegration includes placement in a secure environment, access to a reasonable standard of living, opportunities for personal and economic development, and access to social and emotional support. In many cases, reintegration includes the return of the victim in the original family / community of origin. However, it can also include integration into a new country, depending on the needs and interests of the victim ${ }^{1}$. The services that are offered to the girls victims of trafficking in Albania are divided into two categories:

Residential centers

Community centers (non-residential).

\section{Residential Center}

Otherwise known as residential the host centers, where young victims of trafficking will be able to stay for a short time or even for a longer time. Albania residential centers are open or closed (closed center) ${ }^{2}$.Meanwhile centers open and semiopen give you the opportunity to pursue a professional course, go to work accompanied by center staff or only depending on the security problems that could have any individual. The reintegration center in Albania are: "Different and Equal," Psychosocial Centre "Vatra"; "Another vision" These organizations achieve with the support of three phases:

-Phase I - The first phase is the initial phase which includes accommodation in a residential center, which provides services such as accommodation, housing, clothing, food, medical assistance, legal assistance, psychological services, storage and

\footnotetext{
1 Surtees, Rebecca.2008. Re/integration of trafficked persons: How can our work more effective. Nexus Institute.

2 Closed centers means that girls of trafficking during the accommodation in the center cannot go outside
} 
security 24 hours, vocational training, periodic communication telephone family mediation, family meetings, translation to the foreign beneficiaries transport services, referrals to long-term reintegration alternatives. This first phase of assistance and provide all centers in Albania.

-Phase II - The second phase is the medium phase where the life of the beneficiaries is semi-independent. The organizations like "Hearth", "D \& E" and "Another Vision" in addition to supporting the victims of trafficking, they support them even after they go outside from the shelter by finding accommodation in houses (manner realized by "Hearth" and "Another Vision" organization, and the other manner it the payment of house rent this order applied by the organization "Different \& Equal". These organizations except the part of housing, provides support services such as employment, familiarity with community resources, counseling, etc., these services empower victims are directed towards an independent life.

-Phase III - the third phase is the long- term phase who has as an objective leads to an independent life. This is the last phase which is achieved when a case can live independently.

\section{Not residential services}

Not residential services or community services support the victim of trafficking with their specific programs. These services are provided by day centers that are set up in cities from NGOs and institutions in the state. Day and community services offer several types of services like:

- Legal services and administrative assistance; Ongoing support and monitoring; Psychological services or counseling services; Financial assistance; Professional training; Support to find employment; Medical assistance; Education assistance; Information campaigns; Reintegration into school; Accompaniment during voluntary return ${ }^{1}$

\section{Methodology}

The methodology used in this study is qualitative, as an efficient method that provides a sense of depth exploration of subjects, giving us a much more detailed information and specific. The selected method is also suitable for highly sensitive nature and the delicate issues involved in this study, given that there are few studies in this field. During the study is held into consideration the fact that one element that distinguishes qualitative method quantitatively, that is, the first and the second is deductive, qualitative methods, is inductive. A deductive approach is what passes by a theory or hypothesis in empirical observations to conclusions.

Inductive approach follows the inversion that is when preceding observation hypothesis, theory and interpretation². The instruments that were used are focus groups with girls who actually assisted trafficking victims in the shelter "Vatra"

\section{Why applied the qualitative methods in this study?}

The qualitative methods assists in this delicate cases. Such, disturbing and witty, is the issue of reintegration of victims of trafficking in Albania, not only in the national level, also in the international level as yet has not found the key for the solution of this problem. Qualitative methods used to deepened the issues that interest us, because it gives the opportunity to see the problem in different ways: in our case the conclusion of the process of reintegration with the institutions that provide services directly to the victim of trafficking,

\section{The drafting of the focus group interview}

Focus group interviews may encourage more "the openness" of the respondents and provide information on free and complex. Draft an essential guide is a list of topics or themes to be discussed and that the researcher uses to guide the focus group discussions ${ }^{3}$. Through it, the interviewer stimulate each other with ideas and thoughts. Focus group offers

\footnotetext{
${ }^{1}$ Standard 1: Purpose and types of service standards "Social care services for trafficked persons at risk of being trafficked or residential centers" approved by DCM 195, dt.11.4.2007

2 Jane Ritchie, Jane Lewis, Qualitative Research Practice: A Guide for Social Science Students and Researchers, Sage, 2003, p. 106

${ }^{3}$ Richard A. Krueger, D. L., Morgan, The focus Group Kit. Thousand Oaks, Sage, California, 1998, p. 51 
various data, as panelists encourage communication and promote ideas on how to think and to speak ${ }^{1}$. Through this instrument can be achieved qualitative data. Focus group had up to 8 people participating, because this compound group generates more ideas².

The women victim of trafficking who has been assisted in the "Vatra" center participated in focus group. In realizing of focus groups, the researchers took into consideration what Wells, said ${ }^{3}$ about the ideal size of the group, and how participants sit, style and personality of the facilitators of the meeting in respect of the participants.

\section{Collection and analysis of database}

For the preparation of questions to respondents (women victims of trafficking) are taken into consideration and examined in detail 10 (ten) principles that guide the ethical issues related to the target group under study ${ }^{4}$. The implementation of the study has used the instrument of audio recording of interviews, which helped us to identify who among the respondents is that more active than the rest, as are expressed providers of services related to the program of the process of reintegration offered by them for women victims trafficking.

This method used has helped researchers be concentrated among persons who participated in the study, almost anytime throughout the interviewing process. Recording talks with service providers during the implementation of the focus group has helped us achieve better management of the interview with them ${ }^{5}$. The way to organizing discussions with participants of the focus groups helps researcher at running and determination of collection of data ${ }^{6}$.

The information collected refers to trafficked victims were identified and assisted in reintegration programs, while The researchers have not been able to analyze the information to victims of trafficking cases and unidentified untreated.

From the focus groups conducted with 8 girls victims of trafficking results that the biggest cases girls under the age of 20 25 years.

\section{Age group information of women victims of trafficking}

\begin{tabular}{|l|l|l|c|c|}
\hline Age group & $15-20$ years & $20-25$ years & $25-30$ years & 30 years \\
\hline cases & 1 & 4 & 2 & 1 \\
\hline
\end{tabular}

If we return to a time necessary retrospect, all studies refer to the phenomenon of trafficking associated with the age group $20-25$ years, which constitute $41 \%$ (Study on the socio-economic reintegration of victims of trafficking in Albania, June 2009 , p. 30-32). Even in our study age group 20-25 years is the major cases.

\section{Residential information of the victims of trafficking}

\begin{tabular}{|l|l|l|l|l|}
\hline Birth place & Small town & Urban zone & Rural zone & The foreign \\
\hline Cases & - & 5 & 3 & - \\
\hline
\end{tabular}

If we refer to studies carried in our country shows that the origin of young trafficking victim belongs to the rural areas that make up 58\% (Different and Equal, 2006).

In our study results that large cases (5) young victim of trafficking, belonging to urban areas. This relates to the fact that within these years in Albania has changed the demographic distribution of the population as a result of the migration process. Also, if we refer to the years of the birth of girls, the majority of pregnant women, they give birth at the regional hospital where in were registered.

\footnotetext{
${ }^{1}$ Morgan, D. L., The Focus Group Guidebook, Sage, London,1998, p. 65

2 Edward F. Fern, The Use of Focus Groups for Idea Generation: The Effects of Group Size, Acquaintanceship, and Moderator on

Response Quantity and Quality", Journal of Marketing Research, February, 1982, p. 3

3 William D. Wells, Group Interviewing, Handbook of Marketing Research, 1974, p. 254

4 (WHO ethical and safety recommendations for intervieëing trafficked women. London School of Hygiene and Tropical Medicine,

London: Daphne Program of the EU, 2003).

${ }^{5}$ Edward F. Fern, The Use of Focus Groups for Idea Generation, p.2

${ }^{6}$ Guba, E.G. \& Lincoln,Y.S., Effective Evaluation, Jossey- Bass Publishers, San Francisco, CA, 1981, p. 26.
} 


\section{Information about the legal status of women victims of trafficking}

\begin{tabular}{|l|l|l|l|l|l|}
\hline Legal status & Married & Divorced & Widow & Single & Mother girl \\
\hline Cases & - & 2 & - & 5 & 1 \\
\hline
\end{tabular}

From interviews conducted with women victims of trafficking (WVT), it turns out that the legal status of most of the respondents is "single".

This result is consistent with previous studies where the most cases victims of trafficking were single $(81 \%$ Study on the social-economic reintegration of victims of trafficking in Albania, June 2009, p. 34).

Information about the education of women victim of trafficking:

\begin{tabular}{|l|l|l|l|l|l|}
\hline Education & Without education & $\begin{array}{l}\text { Primary school } \\
\text { finished }\end{array}$ & $\begin{array}{l}\text { Primary school } \\
\text { unfinished }\end{array}$ & Secondary school & Higher education \\
\hline Cases & 1 & 4 & 2 & 1 & - \\
\hline
\end{tabular}

The interviews show that the average educational level of trafficking victims is primary school (consisting of 4 cases). Even in the studies conducted earlier the highest percentage of the victims of trafficking had only primary school $63 \%$ - Different and Equal study, 2009 and $49 \%$ in the annual report of "Vatra" center, 2007)

\subsection{Factors affecting the successful reintegration of the women victim of trafficking}

Based on the focus groups it was found that all the girls interviewed are part of residential services of the center "Vatra". Many of them said they felt safe with strengthened after the services they received from shelters. Below are some pieces of interviews conducted with women victims of trafficking (WvT)

"I'm more empowered to face life only through the support of girls ... " (refers to the employer of Vatra shelter=

"I was helped many services received, I do not know where I would have ended ...."

"I advise girls like me to be part of the services that will be valid for the future ..."

The staff helped me by giving me a hairdressing salon ... I work and live thanks to their support..."

"I can't imagine how my life would be if I had the girls will not help giving up alcohol ...."

"I feel more confident, I have no anxiety and fear for my life and my child ... and thanks to the staff."

"If the center would not have helped at that time, maybe today I would be wandering the streets, infected with various diseases, drugged, probably will not live anymore ..."

From interviews conducted with it emerges that the services were offered by the shelters were in full compliance with their needs. They say they feel safer after the services have been stronger to cope with their lives independently. It was rated as important and fundamental reflection of the main components of the reintegration process, including the review in this way and the main challenges faced by victims of trafficking during the process, as:

Employment, economic and professional situation;

Housing safe and convenient for them;

Family and social relations;

Psychological and physical welfare;

Education and professional development.

Employment, professional and economic situation of the victims of trafficking 
Based on interviews conducted with victims of trafficking girls in Elbasan the results are:

\section{Information about the employment of WvT}

\begin{tabular}{|l|l|l|}
\hline WvT & WvT employed & WvT unemployed \\
\hline Cases & 4 & 4 \\
\hline
\end{tabular}

From interviews conducted with the girls, 4 of them affirm to be employed in the private sector and 4 of them are not currently employed.

\begin{tabular}{|l|l|l|}
\hline WvT employed & WvT satisfied with their work & WvT not satisfied with their work \\
\hline Cases & 1 & 3 \\
\hline
\end{tabular}

The girls' opinions about their employment should be seen in different angles. It result that only a girl feel satisfied with her work.

"The work I do makes me feel better ... .i am satisfied with the work $i$ do, there $i$ have made new friend and learn how to sew a beautiful dress ... "said WvT employed in beauty salon" Vatra "in Vlora.

During the interviews three girls said they were not satisfied with the work they did. This came as a result of not financial motivation from the work, and e make low wages; feeling discriminated in the work environment; the failure of a proper relationship between the employer and the employee. They said:

"I work 10 hours a day without rest and eventually paid 120,000 Lek (85 euro). Unable to pay the rent and could not cherish children. I will be interested to find another job with higher pay.... ", said Wvt which work as a sanitary in o local city.

"I have two months working in a clothing store and the owner treated me well. Someone had said that $i$ stand in the center. Since that day she requires reasons so i leave work ... " said WvT employed in a boutique," Vatra "in Vlora.

"My boss behaves sometimes good with me, sometimes he yell at me for being late at work... We are human... sometimes we don't want to get out of bed..... than he started...."do this job" without finishing the work that $i$ was doing ... .no let me drink a coffee with friends during work hours .... I am very upset, I will leave this job just when I find another job" ...said the WvT employed as kitchen helper.

Girls' employment sector was the private sector as they have been unable to find an employment in the public sector. 4 of reasons why girls were not employed are: caring young children, healthy reasons, and safety reasons. All of this related to the failure to find a job due to economic crisis: they said:

"I am searching for a job for two weeks around the city and have not found work yet ... I am very sad ...."

"I am not searching a job in this moment... I have two month baby and I have no one to hold me or the kindergarten does not accept in this age .....ah how I would like to work, to earn money for myself and my children .... ", expressed WvT who has two children, a 4 years old son and two-month-old daughter,

"It hurts the body all the time, I have terrible bone pain ... I do every month depending (medicine for rheumatism). I am not able to work ... "..

I am not searching a job in this moment, I have fear (from the pimp) that will kill me ....", said the women victim of trafficking in "Vatra" center in Vlora.

The study demonstrates the difficult economic situation and social facing girls in their daily life and the huge impact that this situation is in the process of reintegration. Extremely difficult economic situation affects the lives of young victims of trafficking. 


\section{Safe and convenient housing for the victims of trafficking}

Housing remains one of the most fundamental components in the process of reintegration of WvT. Having a safe shelter and adequate directly linked with positive feelings for the WvT girls themselves have the perception of the future. Housing is considered important as it relates to their own safety as well as their sustainability towards an independent life. When the victim does not fulfill themselves this component, the chances that they become part of trafficking again, are higher compared with its own who meet this component.

\section{Information about the housing of Wvt}

\begin{tabular}{|l|l|l|}
\hline Housing of Wvt & Wvt assisted in shelter & $\begin{array}{l}\text { WvT assist in the autonomous apartments paid by } \\
\text { Shelter }\end{array}$ \\
\hline Cases & 6 & 2 \\
\hline
\end{tabular}

Based on interviews conducted with women victims of trafficking emerges that two women lives in the shelter and the other two lives in autonomous apartments paid by shelters. Based on interviews confirmed that the girls who lives in autonomous apartments paid by shelters and are financially supported by shelters have been easier integrate into society. They said:

"Is the center who paid my rent and they are my big supports...." said the women lives in autonomous apartments paid by shelters donators "Vatra" in Vlora.

"I live in an apartment paid by the shelter and $i$ live alone. I am very satisfied, but I know one day this aid will end. I shall find difficult to afford the life by myself with only the monthly income..." said the women assisted by the "Vatra" center.

Based on interviews, it turns out that when their housing is inadequate, there have been cases where girls have fallen prey to trafficking again, being recycled into society. The interviews showed that two of the girls WvT are recycled into society, becoming again a part of human trafficking for sexual exploitation. Woman victim of trafficking recall moments from their lives:

"After a period of 1 year in the center, has came the moment when i needed to leave the shelter, because i had benefited all services that provide the center. With two children $i$ was settled in a rented apartment and payed by myself the rent (70,000 per month). I worked as assistant cook in a restaurant where they paid me 150,000 a month. I could not feed my children neither with bread. I left the job and started in a bar in the periphery of the town as a waitress, but with the same salary. The bar owner promised to help me economically. He began to bring me customers and $i$ worked for. In this way, $i$ returned again in the profession.... ", Says one women, which is recycled and is currently at the center" Vatra "in Vlora.

"After $i$ stayed tow years in the center e had taken all of the services, $i$ worked as a hairdressing and have raise money to make an independent life. I rent a house that cost 100,000 lek in a month. After two months cause of my bad management, $i$ don't have any money. I was too embarrassed to go to the center and tell them $i$ had no money to pay the rent. Neither to my boss i can not ask money because I woe to him150.000 lek. Situated in this situation, i met a guy and i explicated to him my situation. He told me he's gone help me. After weeks he rent o house for me and then I realized that I was beginning to work for him. I had no choice, must live ... "said the women WvT, after recycling was assisted "Vatra" to the center in Vlora.

"The center girls was very kind with me, but $i$ was upset sitting all the time with other people. I can't stand the women with their children so $i$ decided to leave the center. I rent o house in the center for 80.000 lek in a month. I could not afford to pay the rent the last months. Two young men offer me a job as a cleaner in one hotel. I doubt for the intentions so I asked for help to the girl of the center, they helped me with the payment of the rent...." said the WvT.

From the interviews conducted emerges that the safe housing is a very important element in the process of a successful reintegration of the women victims of trafficking. 


\section{Family and social relations of the victims of trafficking}

The relationship with the family is a very important component in the process of reintegration and, if this relationship is healthy and supportive, the victim is more easily reintegrated into society

\section{Information about the family origin of the WvT}

\begin{tabular}{|l|l|l|}
\hline WVT & $\begin{array}{l}\text { WvT which maintain contact with the } \\
\text { family of origin }\end{array}$ & $\begin{array}{l}\text { WvT which doesn't maintain contact } \\
\text { with the family of origin }\end{array}$ \\
\hline Cases & 5 & 3 \\
\hline
\end{tabular}

Based on interviews conducted with WvT results that 5 cases have decided to keep good relationship with their family of origin. These cases result to have more chance to reintegrate into in society successfully. The family support helps victims of trafficking to be empowered and ready to face the other challenges of this process. Some of the girls have a positive attitude about the relationship they have with their families:

"Establishing contacts with my mother thanks to girl of the shelter _ will help me in the future to return home to get rid of bad road. Today I continue school to pursue my passions (paintings) ... ", says 16-years old girl assisted in "Vatra " center in Vlora.

"During the stay time in the shelter the operators helped me to establish relationships with my family. After leaving the shelter they will receive me home again, although they lived in the village where we see you differently. They will help me to create my new family to outstrip my past.... ", expressed WVT assisted in "Vatra" center in Vlora.

"After exiting the organization will go to my family. The staff of the center will help me and my family to open o small business (bakery) where we will work all together ... ", expressed WvT assisted in "Vatra" center in Vlora.

The interviews show that 3 cases have no relationship with the family of origin

\begin{tabular}{|l|l|l|}
\hline Wvt & WvT rejected by the family of origin & $\begin{array}{l}\text { WvT not wanting to keep in touch with the } \\
\text { family of origin }\end{array}$ \\
\hline Cases & 1 & 2 \\
\hline
\end{tabular}

The girl rejected by their family of origin stated that:

"My family could not accept the fact that $i$ was exploited and ask help and lives in the center. Despite that staff made efforts to establish contacts with them, they refused and refuse even to this day when they spent three years ... ", expressed WvT assisted in "Vatra" center in Vlora.

The interviews showed that the two girls did not wish to maintain the relationship with the family of origin for reasons relating to: family incest.

"My brother, when he was under the influence of alcohol, has tried many times to have sexual relations with me. Bring home and his friends who tried to have intercourse with me ... ", said the

"He (stepfather) raped me when my mother was not at home. When I told my mom, she did not believe me and beat me. He wanted to show that in fact had been a boy from the village. At that time I was only 10 years old ... ", remember the women vicktim of trafficking

The relationship with the family is an important element in the process of reintegration of girls in society. If this relationship is complex and conflicting, as it happens, it is very difficult for the victim to cross the state in which it is located.

\section{The safety of victims of trafficking}

Despite traffic victims receive legal assistance from shelters and subsequent monitoring, they still feel vulnerable because traffickers are free and they have no protection from the state. Based on the interviews, one girl said:

"I do not feel safe to live independently. I fear that my tutors are free. If they see me on the street, they will kill me ... ", 
This finding shows that these girls are victims of trafficking do not become part of the reintegration process. Albanian state has not developed social policies to assist this target group.

But the study found that the majority of WvT interviewed feel safe to live independently, because they have enough information and know where to turn for help. They feel empowered by the services received. Girls say:

"Thanks to the service I got from the shelter, now know how to protect myself ..." says a girl

"I feel empowered ..." said a girl

"I won instruments to defend himself ..." says a girl

\section{Education and professional development of the victims of trafficking}

From the studies and the result of the interviews emerge that the most girl victim of trafficking have only the basic education. This fact makes difficult their process of reintegration in the society. Vocational courses has helped finding o job the women victim of trafficking when thei lived in the shelter. Professional courses offered to victims of trafficking services are tailoring, hairdressing, sitter, kitchen, etc. These professions which are equipped girls are professions that do not provide sufficient income in Albania, ranking lower paid sector. This fact has a direct impact on their daily lives. What will ensure a better future is reinsertion into the school system, but again, this fact is related to several factors such as age, years of school-, desire and willingness to return to school, etc. One girl says:

"I do not have any education, only two professional certificate course ... i wish $i$ will find o job .... ".

The study proves that the certification of professional courses during assisting the victim of trafficking in the center, helped the girls to find a job.

\section{Conclusions}

The study claims that the factors impede the realization of the process of reintegration in society of women victim of trafficking are social and economic factors;

A finding of this study is the effectiveness of shelters that offer complete packages of quality services, short and long term reintegration in the country;

Deemed important the relationship and the support provided to the family of origin. How friendly are these relationships, more the WVT go toward his positive process. Positive family relationship often serves as motivation WvT to move forward in their lives independently. In cases where families have been part of the process of trafficking them or abusing them in childhood, in these cases they do not want to restore relations with them;

A finding in of this paper is appreciated the establishment of a healthy relationship with society of the girls as an important element of the process of reintegration. The women victim of trafficking who have managed to establish positive social relationships with trustworthy individuals, then the possibility of these girls for recycling is much less than girls who can not establish healthy relationship;

A real challenge to successfully implement the process of reintegration in society, remains their employment. Employment is a significant indicator of its sustainability as an individual. If a WvT finds a suitable job and safe, there are bigger spaces to empower independently. Employment is not always reaching WvT is sufficient to meet the cost of life. Here we refer to low pay, schedules prolonged poor conditions of work;

This study demonstrates that an important element is the provision of vocational training in order to have facilities in finding a job on the basis of exchange with which they are equipped. This serves for the girls as job security in the future. It is important to note that professional course offered must be in accordance with the wishes and personal skills of the WvT;

The study indicates that if the women victim of trafficking have a safety housing, a suitable employment, education and vocational training, are supported by family of origin and friends, then they have bigger premises to achieve a successful reintegration process.

\section{Recommendations}

Recommendations to the policy makers: 
Should be taken measures to combat and punish the traffickers and the crime organization. If the legislation is impelmented the women victim of traffcking feel more saifer;

Financial Compensation of WvT. A form of compensation would be that the Albanian government confiscate the property of the tutor and give it to the women victim of trafficking;.

Ensuring the physical safety of all victims of trafficking regardless of whether collaborating with the justice system;

Improving national and international bilateral legal, judicial and law enforcement in the fight against human trafficking;

Be implemented the new strategy carefully in Combating Trafficking in Human Beings (2014-2017) and sets up monitoring by the relevant institutions in the implementation of this strategy;

Albanian state, through to the function of municipalities, has introduced the law No.9232, dated 13.05.2004, for the benefit of social housing for families with socio-economic difficulties. Part of the benefit of this law should be and girls victims of trafficking, as one of the most vulnerable categories of society;

Since employment is a crucial element in the process of reintegration and the biggest difficulty remains into the labor market, it is imperative to have an effective collaboration of the Regional Employment Office. This category should be considered one on the highest priority;

The State shall evaluate the possibility through various donors, such as the provision of microcredit as an alternative employment. Since WvT employment market is limited and wages are minimal, this service would help to secure employment with higher incomes;

VoT should have access to health services. In reality there is a law where health services for victims of trafficking are free, but many health workers in the area lack the the knowledge of the law. The state should be more involved through meetings, seminars and roundtables to inform the representatives of state institutions connected to his own advantage in the scheme of free health services.

\section{Recommendations for service providers:}

Strengthen programs providing assistance to long-term, aiming at the reintegration and social inclusion of young victims of trafficking, in accordance with individual needs;

Ensuring psychosocial legal, health services, and the continued support of victims of trafficking for their reintegration in social life, including services to prevent crises such as to facilitate the use of social services, social assistance, housing, Sharing of Information groups and persons in need, as well as training for life;

ncrease public awareness on all forms of trafficking in persons (trafficking for sexual exploitation, labor exploitation, child begging, etc.);

Improve the prevention of trafficking in women through the strengthening of protectiv systems, creating opportunities other socio-economic and lifestyle opportunities, as well as raising awareness of the wider community;

To ensure continuous monitoring of all the main stakeholders in the Fight Against Trafficking in Human Beings and the measures taken in the country, as well as increased promotion of information exchange between all partner organizations, state and non-state.

\section{Bibliography}

[1] Edward F. Fern, The Use of Focus Groups for Idea Generation: The Effects of Group Size, Acquaintanceship, and Moderator on Response Quantity and Quality", Journal of Marketing Research, February, 1982, p. 3

[2] Guba, E.G. \& Lincoln,Y.S., Effective Evaluation, Jossey- Bass Publishers, San Francisco, CA, 1981, p. 26.

[3] Jane Ritchie, Jane Lewis, Qualitative Research Practise: A Guide for Social Science Students and Researchers, Sage, 2003, p. 106.

[4] Morgan, D. L., The Focus Group Guidebook, Sage, London,1998, p. 65.

[5] Richard A. Krueger, D. L., Morgan, The focus Group Kit. Thousand Oaks, Sage, California, 1998, p. 51

[6] Surtees, Rebecca.2008. Re/integration of trafficked persons: How can our work more effective. Nexus Institute.

[7] William, D. Wells, Group Interviewing, Handbook of Marketing Research, 1974, p. 254 